Ministry of Education Iraqi Directorate of Education Baghdad Karkh III

First Conference Department of Preparation and Training Division of Research and Studies

وزارة التربية العراقية مديرية تربية بغداد الكرخ الثالثة الهؤتمر الاول قسم الاعداد والتدريب شعبة البحوث والدراسات

\title{
Effect of friendship on adolescence (school Al-Fayhaa Model)
}

\author{
Maryam Majeed Abdullah \\ Directorate of Baghdad Education Karkh III, Ministry of Education, Baghdad, Iraq \\ maryam71majeed@gmail.com
}

\begin{abstract}
This research aims to reveal friendship, its role in the life of the teenager, how to choose for friends, The first requirement was to define the meaning of friendship and adolescence in terms of language and terminology, and the second requirement in: Effect of friendship negatively and positively, and made the second topic: about the problems of the adolescent The second was a set of questionnaires about the relationship between the adolescent and his friends, and the end of the conclusion included a summary of what I found and mentioned results and recommendations, and the results resulted in no significant differences in me Adolescents.
\end{abstract}

Keywords: Friendship, teenager.

\section{نأثثير الصداقة على الهراهق (مدرسة الفيحاء نموذجاً)}

\author{
مريم مجيد عبدالله \\ وزارة التربية، مديرية تربية بغداد الكرخ الثالثة، بغداد، العراق \\ maryam71majeed@gmail.com
}

المستخلص يهدف هذا البحث الى الكشف عن الصداقة ، ودورها في حياة المراهق، وكيفية اختياره للأصدقاء، واستخدمت لذلك منهج وصفي تحليلي، وقد شهل البحث على مقدمة وهبحثين، الاول: عن ين صداقة المراهق وتأثيرها سلبا وايجاباً فيه وذكرت في الهطلب الاول: تعريف معنى الصداقة والمراهقة لغة واصطلاحا، والهطلب الثاني في: تأثير الصداقة سلباً وايجابا، وجعلت الهبحث الثاني :عن مشاكل المراهق اسبابها ونتائجها واستبيان علاقته بالأصدقاء، وكان من مطلبين الاول: مشاكل الهراهق أسبابها ونتائجها وعلاجها، والثاني: عبارة عن مجموعة استبانات حول علاقة المراهق بأصدقائه، وأنهيته بخاتمة

شملت خلاصة ما توصلت اليه وذكرته بشكل نتائج وتوصيات، واسفرت النتائج عن عدم وجود فروق جوهرية بين المراهقين.

الكلمات الدالة: الصد/قة، المراهق.

Abdullah, M. (2019). Effect of friendship on adolescence (school Al-Fayhaa Model). Journal Port Science Research, 2(3), 357-374. doi.org/10.36371/port.2018.02.3.2 
الحمد الله العظيم الهنان الذي رزقنا الايمان وعلمنا القرآن وأكرمنا بنور العلم المبدد لظلمات الجهالة

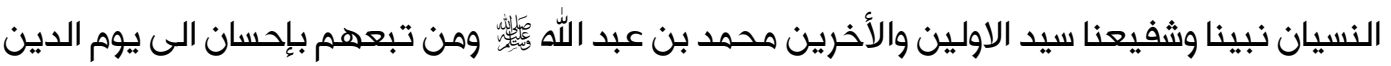
وبعد. تعد الصداقة من القيم الانسانية التي ترتقي بصلاحها الهجتمعات، ويثبت بها الفرد وجوده بين الجماعة، وهذه العلاقة السامية امل وانجاز؛ لأنها تجعل الفرد يتخلص من سلوك الانانية ويأخذ بسلوك الوفاء والاخلاص؛ لأنها متى ما كانت سليمة تكون بمثابة حماية من الوقوع في الخطأوالعكس صحيح، وقد حاولت ان أسلط الضوء على النقاط الههمة في شخصية المراهق ومشاكله وكيفية التعامل معه في سبيل ايجاد أفضل الطرق والاساليب للتعامل معه من اجل خلق شاب سوي ينفع نفسه ويخدم بلده. تعد الصداقة من القيم الانسانية التي ترتقي بصلاحها المجتمعات، ويثبت بها الفرد وجوده بين الجماعة، وهذه العلاقة السامية امل وانجاز؛ لأنها تجعل الفرد يتخلص من سلوك الانانية ويأخذ بسلوك الوفاء والاخلاص؛ لأنها متى ما كانت سليمة تكون بمثابة حماية من الوقوع في الخطأوالعكس صحيح، وقد حاولت ان أسلط الضوء على النقاط الههمة في شخصية الهراهق ومشاكله وكيفية التعامل معه في سبيل ايجاد أفضل الطرق والاساليب للتعامل معه من اجل خلق شاب سوي

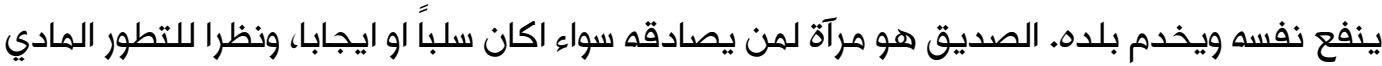
الحاصل فهناك من يرى بان الصداقة الحقيقية لم تعد موجودة، فمشكلات البحث تكمن بنظرة المراهق الى الصداقة، وما هي المعايير التي يختار المراهق اساسا في صداقته.

\section{• • • أهمية الموضوع وسبب اختياره}

هو اظهار اهمية الصداقة لأنها ذات علاقة راقية تحدد علاقة الفرد بالآخرين، وان العلاقة السليمة تؤدي الى نجاح المراهق وعبور هذه المرحلة بشكل امن، وتعزيز قيمة الصداقة.

\section{اهداف البحث فرضياته}

يهدف البحث الى توضيح علاقة المراهق بأصدقائه، وانه لا توجد موانع من اقامة علاقة صداقة حقيقية ضمن إطار سليم، ويتضح ذلك من خلال أجابته على محاور الاستبيان في الاسئلة التالية:

$$
\begin{aligned}
& \text { (1) اختيار الاصدقاء } \\
& \text { خصائص الاصدقاء } \\
& \text { دور الاصدقاء في حياة المراهق. } \\
& \text { حدود البحث }
\end{aligned}
$$

استخدمت في البحث شريحة محددة للدراسة اقتصرت على طلاب الثالث المتوسط؛ لمحاولة فهم معنى الصداقة في هذه المرحلة، ولضيق الوقت لم اجمع معها مرحلة او مدرسة اخرى.

عبدالله، مريم مجيد. (2019). تأثير الصداقة على المراهق (مدرسة الفيحاء نموذجاً). Journal Port Science Research، doi.org/10.36371/port.2018.02.3.2 .374-357 ، (3)2 
الصداقة هي علاقة اجتماعية تربط بين شخصين او أكثر وتكون مبنية على اساس الثقة والتعاون وتبدأ بمرحلة عمرية مبكرة لكنها تكون في اوجها في مرحلة المراهقة؛ لأنها مرحلة حساسة تتميز بطغيان العواطف والاحاسيس، وقد فصلت القول عن مصطلحات البحث في المبحث الاول.

\section{الإطار النظري والدراسات السابقة}

بعد البحث والتتبع الدقيق في المكتبات والمنشورات العلمية وفي الشبكة العالمية (الأنترنت) وغيره وسؤال أهل الخبرة والاختصاص، فوجدت عدد من البحوث التي سبقني بها أهل الاختصاص في الكتابة عن هذا الموضوع لكني لم اعثر على من تناول الموضوع بالشكل الذي تطرقت اليه من خلال استبيانات ميدانية حقيقية، وقد افادني بعمل جداول الاستبانة متفضلاً أ. د. حسين الطائي أستاذ في هن هني

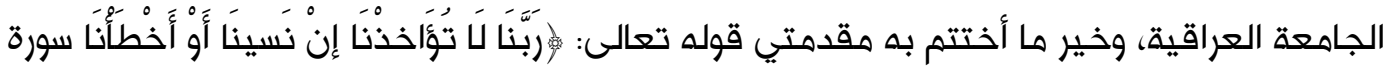
البقرة : من الآية 286 والله ولي التوفيق.

\section{المبحث الأول \\ صداقة المراهت وتأثيرها سلباً وايجاباً}

المطلب الاول تعريف معنى الصداقة والمراهقة لغة واصطلاحا:

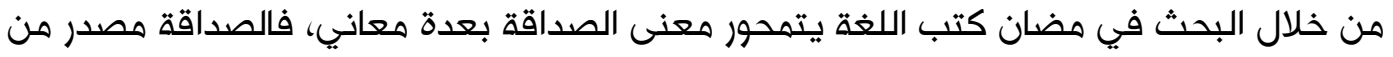

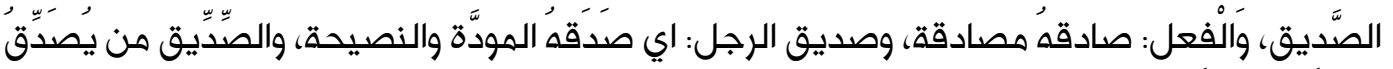

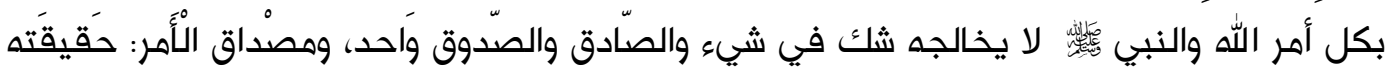

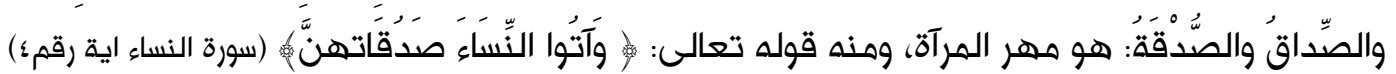

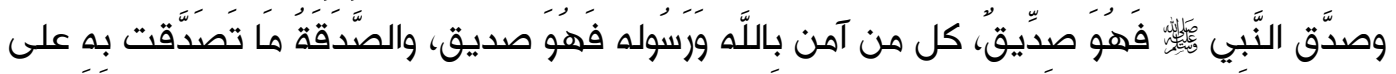

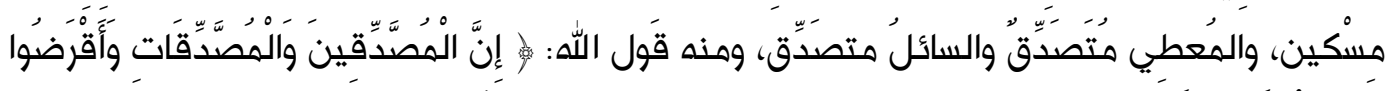

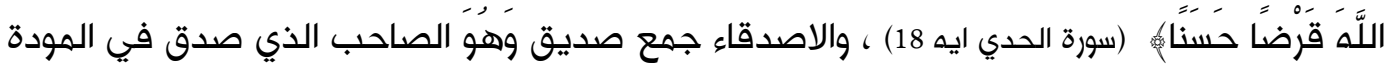

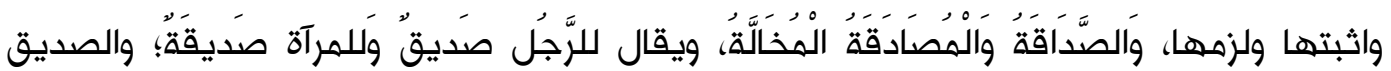

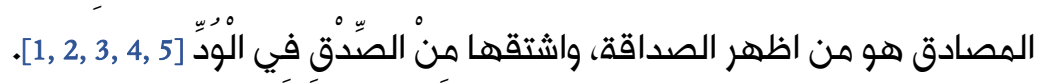

الصديق اصطلاحا: الصديق اصطلاحا: هو الحميم القريب المشفق على صاحبه، والقريب من الروح والقلب فيكون له الأثر الكبير على صاحبه سواء اكان سلبا او ايجاباً فوجب علينا الحذر عند اختيار الصديق بدقة، فقد يكون له اثار على صاحبه لا يحمد عقباه [6]. الجرجاني، فمن خلال تتبع المعاني اللغوية والاصطلاحي يتبين تساوي معنى الصديق.

Abdullah, M. (2019). Effect of friendship on adolescence (school Al-Fayhaa Model). Journal Port Science Research, 2(3), 357-374. doi.org/10.36371/port.2018.02.3.2 


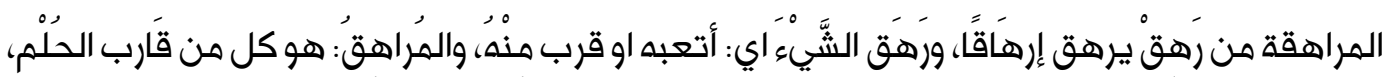

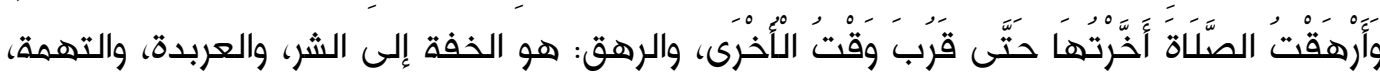
والإثم، والظلم، والهلاك، والكذب، والحمق، والجهل، وخفة العقل، والكبر والعظمة، والعجلة، والسفه، وتحمل الإنسان ما لا يطيقه، وسنّّ المراهقة: مرحلة من مراحل عُمر الإنسان، تبدأ عند البلوغ الحلم

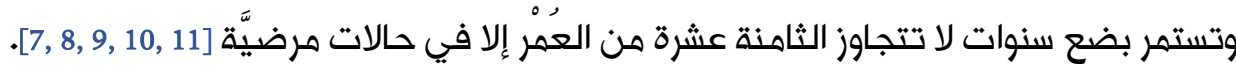

\section{المراهقة اصطلاحاً:}

تعد مرحلة المراهقة فترة عبور وانتقال من مرحلة الطفولة الى مرحلة الشباب، فيبدأ الاهتمام بالهظهر فنجد المراهق يقف كثيراً اماما المرآة ويهتم بذاته وبغيره، وتتخذ المراهقة ثلاثة ابعاد بعد بيولوجية، واجتماعية، ونفسية فيحاول معرفة العالم من حوله فتبدأ المراهقة واحياناً لا تكون بدايتها واضحة، لهماهرة اما نهايتها فتكون مع تماما النضج الاجتماعي دون تحديد ما وصل اليه المراهق من هذا النضج [12].

$$
\text { وعرف اهل العلم الهراهق بعدة تعريفات منها: }
$$

1) بانه:" ذلك الفرد الذي تقع سنه بين سن البلوغ وسن الاعتماد على النفس اقتصادياً. ويشمل هذا التعريف الذكر فقط اما الانثى، فان فترة المراهقة هي تلك الفترة التي تقع بين سن البلوغ وسن

$$
\text { الزواج" [13] (نوري1990) ص22. }
$$

2) وبتعريف اخر ان المراهق هو "الطفل الصغير الى حدود سن الرابعة عشر تقريبا يجتاز طورا من النمو شبيه بالمرحلة البدائية في تاريخ الانسانية وهو قريب من الحيوان كنوع لكن معظم المهارات الحسية- الحركية في هذا الطور تسعى الى حفظ ذاته، وفترة المراهقة بدورها فترة مماثلة للفترة التاريخية من ماضي الانسان، وهي الفترة التي كان يعمل من خلالها للارتقاء بنفسه

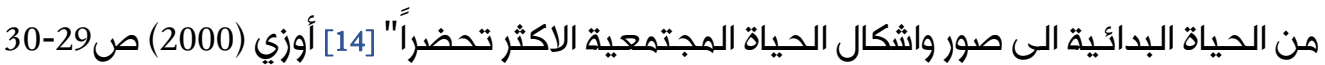
3) ومعنى المراهق "ان الانسان منذ ميلاده الى اكتمال نضجه يميل الى الادوار التي مر بها تطور الحضارة البشرية منذ ظهور الانسان الى الآن" [15] القوصي1987 ص 232. 4) المراهقة تعني "التدرج نحو الرشد بكافة أوجهه" [16] عبد القادر طه 408.

وفترة المراهقة تكون أصعب فترة زمنية يمر بها المراهق، فيها التغيرات الجسمية والنفسية والسلوكية وغيرها فاذا أحسن الوالدان التعامل مع الأبناء في هذه المرحلة، فستنتهي بأفضل النتائج، بتكوين الشخصية المستقلة الخالية من الأمراض النفسية، وإن تعامل الوالدان مع هذه المرحلة بجهل ؛ تكون فيما بعد شخصاً يتصف بالعدوانية والعناد، وعدم التصالح مع الذات، وهن الامور الههمة الواجب على الاباء الانتباه اليها هي أصدقاء المراهق التي قد تكون السبب في نجاحه بتخطي هذه 
المرحلة او الفشل لان هذه المرحلة مهمة في تكوين العلاقات والصدقات، ولها الاثر الكبير في بناء

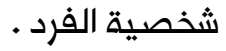

\section{الهطلب الثاني: تأثير الصداقة على الانسان سلباً وايجاباً}

إن الإنسان مدني بطبعه، يحب أن يخالط الناس، ويتخذ الأخلاء والأصدقاء، والصديق يؤثر على صديقه سلباً أو إيجاباً، ولاسيما في مرحلة المراهقة، فالصديق لونان نوعان:

النوع الاول صديق فاسد يزين لصاحبه سوء الأعمال، ويدعوه إلى قبيح الخصال، ويقوده إلى مهاوي

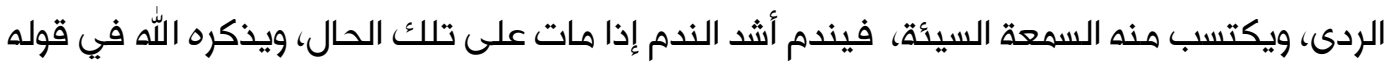

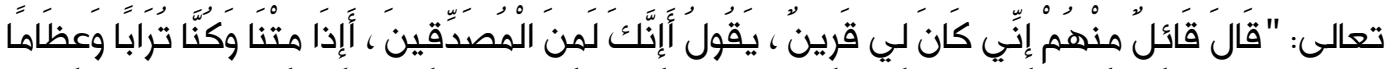

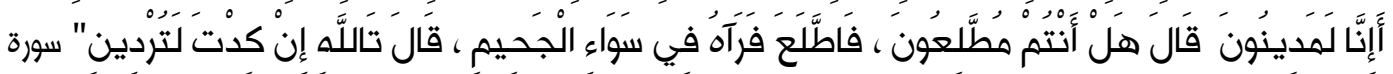

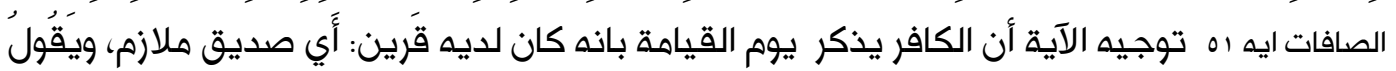
انه كان صادقاً فيما يقول عن بالبعث وَالْجَزَاء [17].

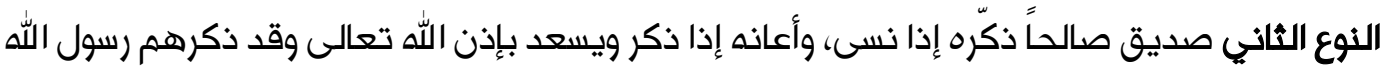

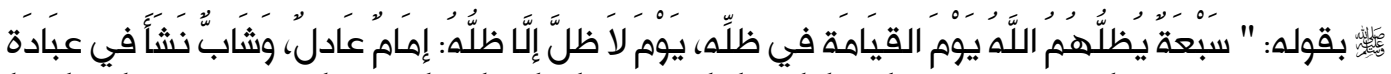

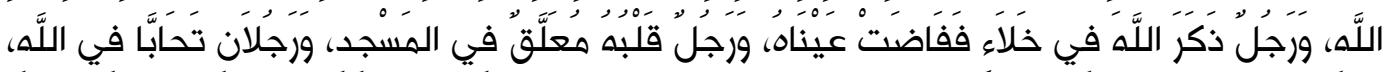

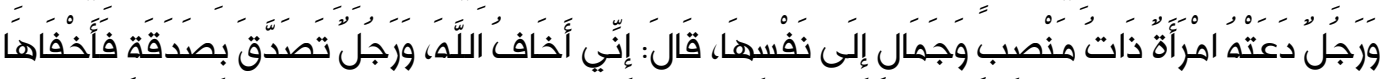

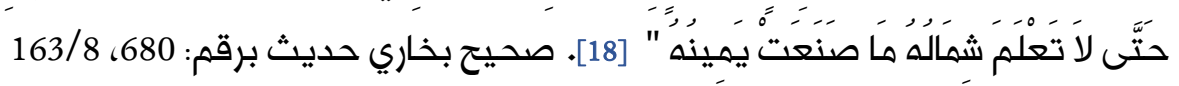
فالأصدقاءُ من أهم المؤثرين في سلوك الهراهق ، فقد يكـون تأثيره أحيـاناً إيجـابيا؛ كإعجـاب الشخص المراهـق بصديقِ متفوّق في مجال من المجالات ويحاول التشبه به، واحياناً اخرى يكون سلبيا وضار؛ كأن يطلب الصديق مـن صديقه الهراهق التغيّب عـن المدرسة معه( وهذا يحدث كثيراً في مدارسنا)، او يطلب منه أن يسرق معه، وهـذا التأثير يضع المراهق في دائرة الخطر، ويحول بيذه وبين

مستقبله.

وكثيراً ما يُسهم الوالدان في دفع أبنائهم المراهقين نحو مجموعة الاصدقاء، وذلك بسبب انشغالها عن تربيتهم وسـد حاجاتهم، أو لكثرة الصراعات والمشاحنات الزوجية، ممّـا يُشعرهم بعدم الاهتمام الأسرة بهم وبإنسانيتهم، فيبحثون خارجها عـن ملاذ آمن، يجدون فيه أنفسهم وحاجتهم للانتماء والرعاية والحنان والشعور بالعائلة، التي افتقدوها في أسرهم، وقد تكون منافسة الأصدقاء في

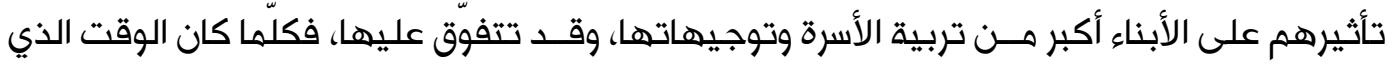

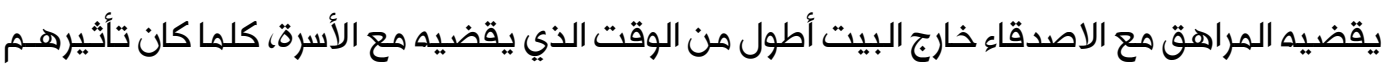
عليه أقوى؛ لذا وجب علينا كآباء وهربين توفير كـل مـا يجذب المراهق إلــى البيت والأسرة، ولأهمية 


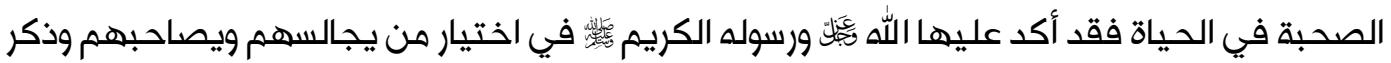
ذلك في مواضع عديدة ولا يسع بحثي هذا ان اذكرها جميعها لذا سأذكر بعض الآيات القرآنية وبعض

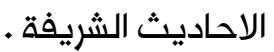

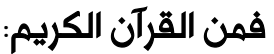

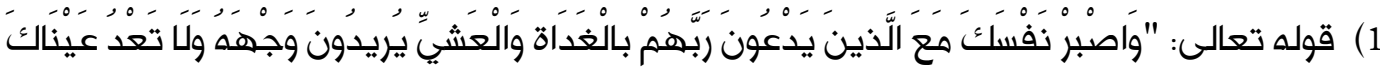

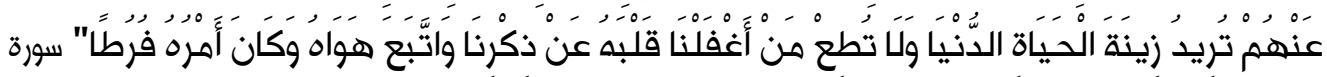

الكهف ايه 28.

وجه الاستدلال: هو مجالسة أهل الذكر الذين يذكرون الله ويهللونه ويحمدونه ويسبحونه ويكبرونه ويفعلون الاعمال الصالحة ولا ينشغلون عن الدين وعبادة ربهم بالدنيا[19].

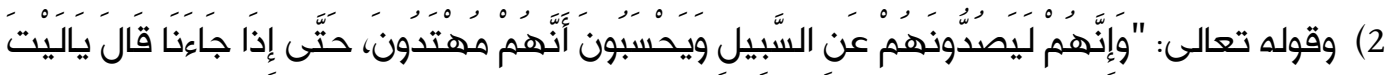

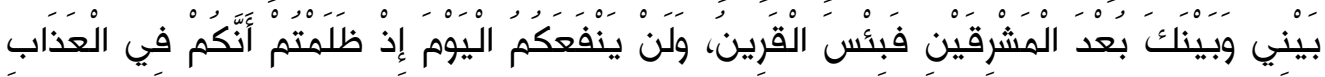

$$
\text { مُشَتِكُونَ" (سورة الزخرف اية 36-37). }
$$

وجه الاستدلال: ان من يتغافل أو يتعام عن النظر في القرآن والعمل به، ومن يعرض عن شرع الله

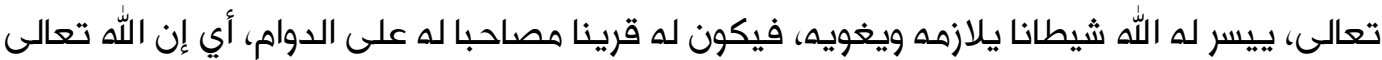
يعاقب على المعصية بالتزيد في المعاصي، وإن الشياطين الذين يقيضهم الله تعالى ويمنعونهم بالوسواس عن سبيل الحق والرشاد، ويحسب الكفار بسبب تلك الوسوسة أنهم مهتدون إلى الحق

$$
\text { والصواب [20]. }
$$

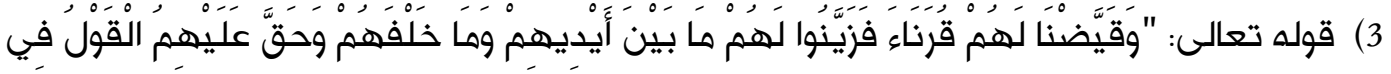

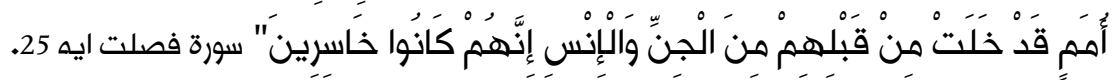

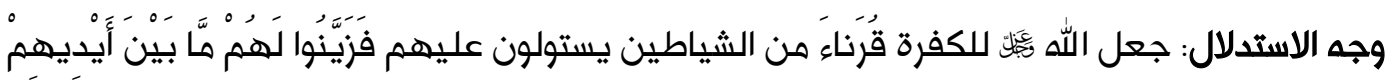

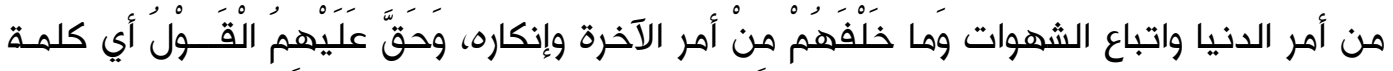

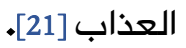

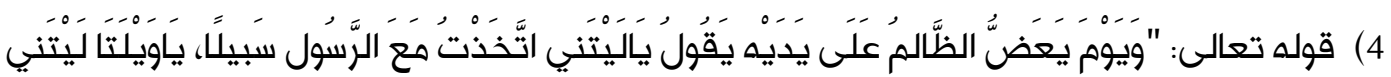

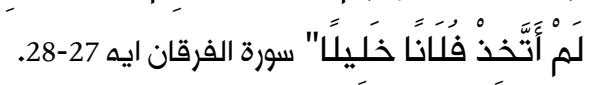

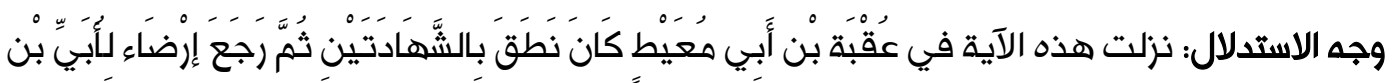

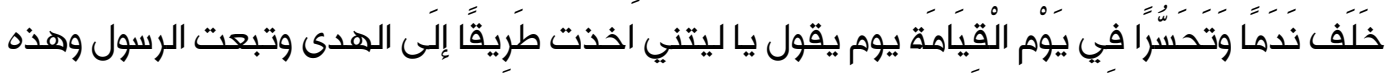


الآية من أعظم الأمثلة التي ذكرها القرآن الكريم على تأثير الصحبة، وبيان خطورتها على

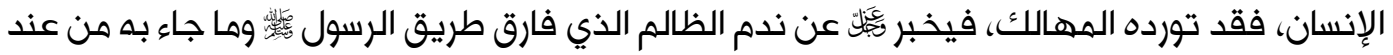
الله من الحق الهبين الذي لا مرية فيه وسلك طريقا أخرى غير سبيل الرسول ندم حيث لا ينفعه الندم وعض على يديه حسرة وأسفا [22, 23].

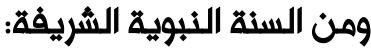

وفي السنة النبوية المطهرة الكثير من الأحاديث التي تبين أهمية اختيار الصاحب والرفيق، وأن من أسباب الخير والصلاح وحصول الفلاح الرفيق الصالح.

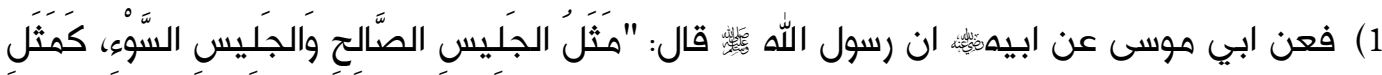

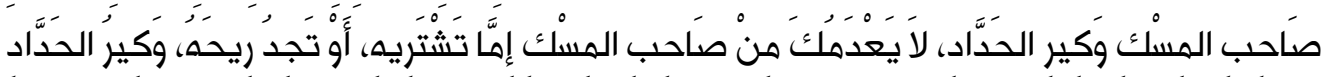

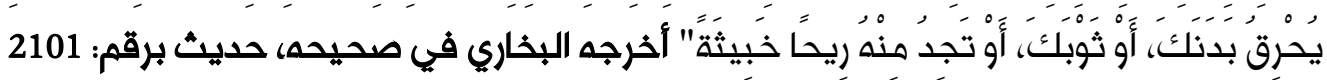
.[24] $663 / 36$

وجه الاستدلال: في الحديث تمثيل من النبي وخطر مجالسة جليس السوء واستحباب مجالسة الصالحين ومجانبة قرناء السواء فقد شبه النبي محمد

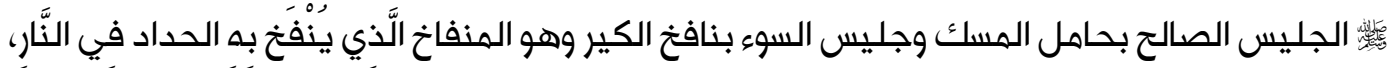
ابن منظور 63/3، وفيه فضيلة مجالسة الصالحين وأهل الخير والمروءة ومكارم الأخلاق والورع والعلم والأدب وتعلم العلم ذكر الله وأفعال البر كلها، والنهي عن مجالسة أهل الشر وأهل البدع ومن يغتاب الناس أو يكثر فجره وبطالته، والخائض في الباطل ونحو ذلك من الأنواع الهذمومة، فصحبة الصالحين والعلماء وأهل الفضل فيها النفع في الدنيا والآخرة، وصحبة الأشرار والفساق تضر في الدين والدنيا

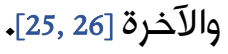

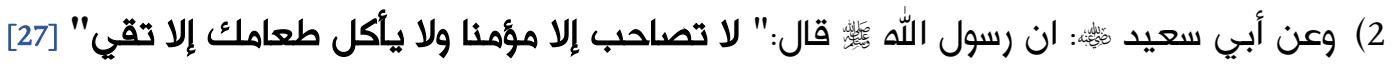
اخرجه الترمذي في سننه، وحسنه، حديث برقم: 600/2395. وجه الاستدلال: تحذير من مصاحبة الكفار ومودتهم ومصاحبتهم ونهى عن مخالطته ومؤاكلته، لأن المطاعمة توقع الألفة والمودة في القلوب، فلا تؤلف من ليس من أهل التقوى والورع؛ لأن الهؤمن هو الذي يعينك على فعل الأعمال الصالحات، أما الصاحب السئ فهو يعيق عن العمل الصالح [28].

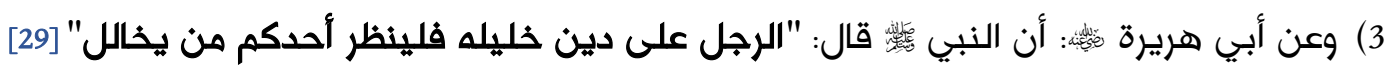
وحسنه الألباني برقم: 5858، 1 / 586.

Abdullah, M. (2019). Effect of friendship on adolescence (school Al-Fayhaa Model). Journal Port Science Research, 2(3), 357-374. doi.org/10.36371/port.2018.02.3.2 
وجه الاستدلال: أكد النبي صاحبه وطريقته وسيرته فليدقق النظر ويتأمل ويتدبر من يخالل فمن رضي دينه وخلقه اتخذه خليلاً

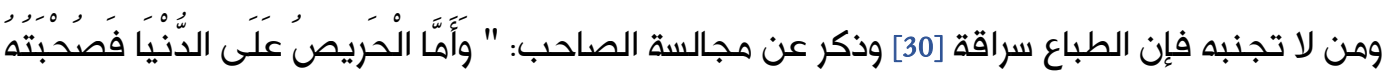

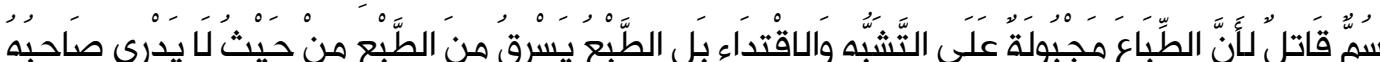
لَ,

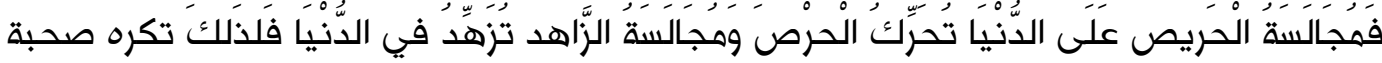
طلاب الدنيا ويستحب صحبة الراغبين في الآخرة "[31] الغزالي 2005 173/2. عن أنس بن مالك بِّئة قال: قال (سول الله مفاتيح للشر مغاليق للخير، فطوبى لمن جعل الله مفاتيح الخير على يديه، وويل لمن جعل الله مفاتيح الشر على يديه" [32] ابن ماجة: 237، 86؛ [33] البيهقي في شعب الإيمان، برقم: 698، 1/

وجه الاستدلال: يرشدنا النبي من في صحبته سبب لكل شر، وتثبيط عن عمل الصلاح إلا من الشر ففي الخير مرضاة الله وفي الشر همر فمراح سخطه فإذا رضي الله عن عبد فعلامة رضاه أن يجعله مفتاحا للخير فتكون عليه من الله سمات ظاهرة لأنه يتقلب في الخير بعمل الخير ولا ينطق بالخير ولا يفكر الا في خير ويضمر خيرا فهو مفتاح الخير حسبها حضر وسبب الخير لكل من صحبه، اما الصاحب السيء يتقلب في شر ويعمل شرا وينطق بشر ويفكر في شر ويضمر شر فهو مفتاح الشر؛ لذا فوصف صحبة الأول بالدواء والثاني بالداء، [34] واكتفي بهذا القدر من الادلة الواردة في القرآن والسنة النبوية المطهرة، وكما ذكرت سابقا ان البحث لا يحتمل ان اكثر من الادلة، وقد اوردت البعض منها لأهمية الموضوع.

\section{المبحث الثاني}

\section{مشاكل المراهق اسبابها ونتائجها واستبيان تعلقه بالأصدقاء}

تعد مرحلة المراهقة نوع من التوقف المؤقت للتغيير الذي يحدث بين مرحلة الطفولة وبين مرحلة الرشد في المجتمع؛ لذا فأننا نلاحظ معاملة الكبار للمراهقين متذبذبة بين الطفولة وبين الرشد [35] وتعتبر مرحلة حساسة وخطرة اذا لم يحسن التعامل فيها مع ولتوضيح الاسباب التي تجعل المراهق يتمرد فيها على كل ما حوله، فقد قسمت هذا المبحث الى مطلبين وسأوضح الاسباب، والنتائج التي تؤدي تمرده، والتعرف على علاقة المراهقين بأصدقائه عن طريق استبيانات توضيحية، لمعرفة التعامل مع هذه الشريحة من ابنائنا للعبور من هذه المرحلة بسلام.

عبدالله، مريم مجيد. (2019). تأثير الصداقة على المراهق (مدرسة الفيحاء نهوذجاً). Journal Port Science Research،

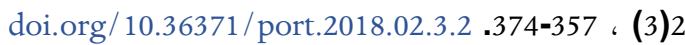




\section{المطلب الاول: مشاكل المراهق أسبابها ونتائجها وعلاجها}

يذكر اهل الاختصاص [36] التغيرات الحاصلة في حياة المراهق التي تؤثر على نفسه وهزاجه المتقلب

1) المراهقة من اصعب الهراحل العمرية التي يمر بها الانسان، فهي فترة عواطف وتوتر شدة تسودها المعاناة والاحباط والقلق والازمات النفسية، ومرحلة انتقال من الطفولة الى الشباب؛ بسبب التغيرات الهرهونية في اجسامهم مما يجعلهم بحالات مزاجية كبيرة وشديدة، كما وان الهناطق المسؤولة عن العاطفة تنضج بسرعة اكبر من تلك المسؤولة عن العقل، وان للمراهقين فروق فردية فمنهم من يكون في هذه المرحلة بمنتهى التدين والصلاح، تبعا للمحيط الذي يعيش فيه، ومنهم من يكون منتهى الانحلال واللامبالاة اذا لم يجد من يفهمه فالأب يشك فيه باستمرار والام مثالية او سريعة الغضب، فيهرب منهم ليبحث عن من يفهمه فاذا وقع في شباك أصدقاء سيأين، فيكون ضحية الاهمال، فوجود الاهل ومواجهة الاتجاهات الشاذة والعادات المدمرة التي

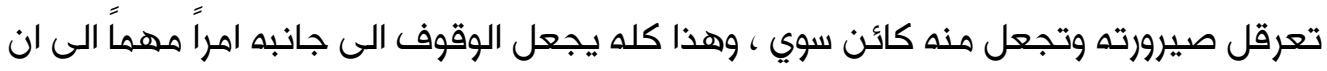
يعبر هذه المرحلة بسلام [37, 38]. 2) ارتباك المراهق والحيرة التي يمر بها؛ لأنه يجد نفسه على نحو مفاجئ أصبح في عدد البالغين، وهع ان العاطفة والغريزة مشتعلة في نفسه وجسهه، فهو عاجز عن تحديد ما يريده، وكثيرا ما يتصرف المراهق كالأطفال، ويريد من الكبار ان يعاملوه كرجل، فاختلاف انفعالاته، ورفضه للخضوع لسلطة الكبار؛ لأنه يشعر بنمو جسهي وعقلي، يجعله يشعر بانه قادر على اتخاذ قراراته

3) لدى المراهق الكثير من النقاء والبراءة فهو مثالي للغاية، ويصبح قادرا على استخدام مفاهيم مجردة، ويحاول تطبيق كل ما يتعلم، وينتقد ما حوله بشكل حاد حتى يصل به الانتقاد الى انكار جهود الاهل في خدمته والانفاق عليه، وعدم نضج الجانب العقلي لديهم هو الذي يجعلهم بهذه المثالية [40]. كما ويظهر المراهق رغبته في الاستقلال كقفل باب غرفته دون سبب، فلا يمكن دخولها دون استأذنه، او عدم بقائه في الهنزل وقت طويل، خاصة في ايام العطل لأنه يعتبر بقائه في المنزل يجعله يتلقى الاوامر، ويسمع، ويطيع، يرضخ لسلطة الكبار. 4) أختلف العلماء على الدور الذي تلعبه فترة المراهقة بالنسبة للنمو الحركي الجسماني فهذه الاضطرابات قد تمتد الى فترة معينة [41] يعتقد البعض ان المراهقين هذا الزمان يختلفون، عن مراهقين الزمان الماضي؛ لذا يتسم موقفهم من المراهقين بالحدة والشكوى، وهذا الراي غير صحيح فكثير من مراهقي هذا الزمان من يقوم الليل ويقرأ القران.

Abdullah, M. (2019). Effect of friendship on adolescence (school Al-Fayhaa Model). Journal Port Science Research, 2(3), 357-374. doi.org/10.36371/port.2018.02.3.2 
5) يبحث المراهق عن جيل ينتمي اليه، يختلف عن ابويه؛ لأنه يشعر بعدم الانتماء الى جيلهم، ويقوم ببعض التصرفات الهلفتة للانتباه، فيرفع صوت الهذياع ويجتمع مع اصحابه في الازقة والشوارع ويضحكون بأصوات عالية، كما يختلق المراهق الهناسبات ليجتمع مع اصحابه، ويتهادى المراهقون بأسباب وبدونها، ويدافع المراهقون عن بعضهم البعض, ويضحي من اجل صاحبه، ويتحمل اخطاءه، ويشعر المراهق بان اصحابه يفهمونه اكثر من ابويه، ويتكلم امامهم عن اسراره، واسرار بيته؛ لانهم اقرب اليه من اهله، وقد يعرف عنه اصحابه ما لا يعرفه عنه ابويه، ويجري المراهق مكالمات طويلة مع اقرانه [42]. 6) التغيرات التي تحدث عند المراهق تؤدي الى عدد من الصراعات، والانفعالات العنيفة في نفسه، كمشاعر النقص والكمال، والصراع بين الاستقامة والانحراف، والتحرر والانضباط، والموضوعية، واكتشافه ان الامور اعقد مما كان يظن بكار [43]. وبعد معرفة الاسباب التي تجعل المراهق يكون بهذا النوع من الازدواجية، لذا وجب استخدام اساليب خاصة للتعامل معه من قبل ذويه تقديراً للمرحلة التي يمر بها منها: 1) تركه يعبر عن أرائه، وعدم الضغط عليه في اعطائه الأوامر، وعدم فرض قيود شديدة عليه وتشجيعه على التعاون مع الاسرة والقيام بالعمل الجماعي، يؤدي الى توسيع خبراته [44, 45]. 2) عدم اللوم والاصغاء الى المراهق من قبل الاب، او الام او الهدرس، يجعله يعترف بأخطائه، ومحاولة احتواءه وفهم مشاعره دون حاجته الى توضيحه، وعدم استخدام العقاب اللفظي والجسدي معه

$$
\text { حتى لا يتولد لديه ازمات نفسية [46]. }
$$

3) عدم احراجه امام زملائه حتى، والسماح له باختيار اصدقائه وتوجيهم، والتأكد من سلامة المعايير الاجتماعية السائدة في اصدقائه، وتشجيعه على تصحيح أخطائه بنفسه فالتجربة خير معلم، والاهتمام بتعليهه القيم السامية والاخلاقية، والروحية، وبتعاون المدرسة والاسرة بذلك. 4) التسامح معه وعدم استعمال القسوة والشدة معه حتى لا ينفر، ولا يعني هذا تركه واظهار الضعف امامه حتى لا يتجاوز حدوده، عدم التحيز بالمعاملة حتى لا يشعر بالفروق الفردية، ومناقشته في قرارته وجعله يتحمل نتيجة قراراته ليكتسب الثقة في نفسه، وينمي الوعي لديه. وفي حالة عدم اتباع هذه الاساليب مع المراهق فان ذلك سيؤثر عليه سلباً مما يجعله لايترك أصدقاءه ويقوم بتقليدهم في كل ما يريدون القيام به، فيصبحون نسخة طبق الأصل عنهم، ويكون مقلداً لهم، الأمر الذي يبدو واضحاً من طريقة تحركه وتكلهه أو اختيار ملابسه وغيرها من الأمور، وقد ينساق الى من يكون ساذجا ويجره الى مشاكل هو في غناء عنها، وقد يلجأ لشخص يستغله ويشجعه على أفعال بعيدة عن الاخلاق والدين، ثم يهدده ولا يستطيع التخلص منه فيرى نفسه اسيراً وتابعاً له، 
فتحذيره من هذه النماذج التي تضره يكون بصورة مباشرة وغيره مباشرة، ومحاولة معرفة اصدقاء المراهق، وبيأتهمم لحمايته منهم ومن نفسه، وينبغي ان يدرك من يرعى المراهق بانه يمر ب "فترة لابد من تهوين شأنها، علينا أن نقر بكيانها كمرحلة ضرورية في التدرج الطبيعي نحو النضج فإن نحن تبنينا مثل هذا الاتجاه نكون قد قدرنا الهراهقة بعد ان تقبلنا إياه على فترة تدريب يتمتع الفرد خلالها بما يستحق من الامتيازات وما هو مؤهل له من مسؤوليات" لجسماني 1994 ص236 [47].

\section{المطلب الثاني: استبانات حول علاقة المراهق بأصدقائه:}

بعد ان ذكرت كل ما يخص المراهق في المطالب السابقة اود ان اوكد ما ذكرته من خلال عمل استبانة موضحة علاقة الهراهق بصديقه مبينة ذلك في الجداول عن طريق شرح النسب وتفاصيلها واخترت لذلك عينة من طلبة مرحلة الثالث المتوسط في متوسطة الفيحاء للبنين، وكان عدد العينة (120) طالب، ولخصت نتائج البحث في جداول بعد معالجتها ببرنامج اكسل واستخراج النتائج النهائية، وقد افدت من بحث ((الصداقة عند الشباب الجامعي)) بالنسبة لبعض اسالة الاستبيان [48].

نتائج البحث كاملة بحسب مجموعة العينة: جدول رقمر (1) توزيع /فراد العينة على النسبة المئوية

\begin{tabular}{|c|c|}
\hline النسبة الهئوية\%٪ & متوسطة الفيحاء للبنين \\
\hline 83,0 & 120 \\
\hline
\end{tabular}

\section{أولا: نتائج الاستبانة لأفراد العينة كاملة}

أظهرت نتائج الاستبانة لإجابات الاستبانة أفراد العينة كاملة، بعد ترتيبها بحسب خيارات الاجابة

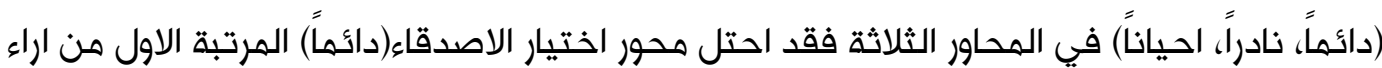
المستفتين، وبنسبة 43\%، وتلاه محور خصائص الاصدقاء وبنسبة 38\% ثم محور دور الاصدقاء في حياة المراهق جاء في الهرتبة الاخيرة بنسبة 18\%، اها من حيث الاجابة ب(نادراً) فقد جاء محور اختيار الاصدقاء في المرتبة الاول ايضاً وبنسبة 27\%، وتلاه محور خصائص الاصدقاء وبنسبة 27\% ثم محور دور الاصدقاء في حياة المراهق جاء في المرتبة الاخيرة ايضاً وبنسبة 0,5، ومن حيث الاجابة ب(احياناً) فقد جاء محور دور الاصدقاء في حياة الهراهق في المرتبة الاول وبنسبة 40٪، ثم تلاه محور خصائص 
وتشير هذه النسب في اطارها العام الى الاهمية التي يعطيها المراهق لاختيار الصيق بالدرجة الاولى ثم دور الصديق وخصائصه، وربها يعود ذلك لشعورهم باختلال المعايير التي تحكم اختيار الاصدقاء، والمرتبطة بخصائص الصداقة الحقيقية لدى المراهق.

جدول رقمر (2) ترتيب نتائج محاور الاستبانة بحسب التكرارات العامة

\begin{tabular}{|c|c|c|c|c|c|c|c|}
\hline الهجموع & 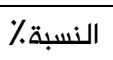 & ك/أحياناً & 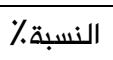 & ك/نادراً & النسبة\%٪ & ك/دائما & المحور \\
\hline 359 & 27 & 90 & 27 & 71 & 43 & 198 & اختيار الاصدقاء \\
\hline 349 & 33 & 113 & 23 & 62 & 38 & 174 & خصائص الاصدقاء \\
\hline 352 & 40 & 135 & 0.5 & 133 & 18 & 84 & دور الاصدقاء في حياة المراهق \\
\hline 1060 & - & 338 & - & 266 & - & 456 & المجموع \\
\hline
\end{tabular}

\section{ثانياً: نتائج استبانة محور اختيار الاصدقاء}

أظهرت نتائج اجابات الطلبة، على البنود الثلاثة في محور اختيار الاصدقاء بان الاجابة ب(دائماً) حصلت على المرتبة الاول في بند أختار أصدقائي بنفسي في (جدول 3)، وبنسبة 48٪، وتلاه بند أومن بوجود الصديق وبنسبة 43\% ثم بند يتدخل أهلي في اختيار أصدقائي جاء في المرتبة الاخيرة بنسبة 17\%، في حين جاء هذا الاخير بالمرتبة الاولى من حيث الاجابة ب(نادراً) وبنسبة 69٪، وتلاه بند أختار أصدقائي بنفسي وبنسبة 17\% ثم بند أوهن بوجود الصديق وبنسبة 14\%كان المرتبة الاخيرة، ومن حيث الاجابة ب(احياناً) فقد جاء بند يتدخل أهلي في اختيار أصدقائي مرة اخرى في الهرتبة الاولى وبنسبة 53\%، ثم وتلاه بند أومن بوجود الصديق وبنسبة 25٪ ، وترجع محور اختيار الاصدقاء حيث جاء في المرتبة الاخيرة وبنسبة 12\%، ونتيجة لهذا التفاوت كان مجموع الاجابة بتكرار(دائماً) 198مقابل161 بلاء لتكرار(نادراً، واحياناً) وهو اعلى من مجموع التكرارين معاً.

جدول رقمر (3) اجابات عينة بنود محور (اختيار الاصدقاء)

\begin{tabular}{|c|c|c|c|c|c|c|}
\hline النسبة.\% & ك/ احياناً & النسبة\% & ك/نادرا & النسبة\% & ك/ كائما & البنود البود \\
\hline 28 & 25 & 14 & 10 & 43 & 85 & أومن بوجود الصديق \\
\hline 13 & 12 & 17 & 12 & 48 & 96 & أختار أصدقائي بنفسي \\
\hline 59 & 53 & 69 & 49 & 9 & 17 & يتدخل أهلي في اختيار أصدقائي \\
\hline- & 90 & - & 71 & - & 198 & المجموع \\
\hline
\end{tabular}

عبدالله، مريه مجيد. (3519)، (2019). تأثير الصداقة على المراهق (مدرسة الفيحاء نموذجاً). Journal Port Science Research، 
ثالثا: نتأُج استبانة محور خصائص الاصدقاء

أظهرت نتائج اجابات الطلبة، على البنود الثلاثة في محور خصائص الاصدقاء بان الاجابة ب(دائماً)

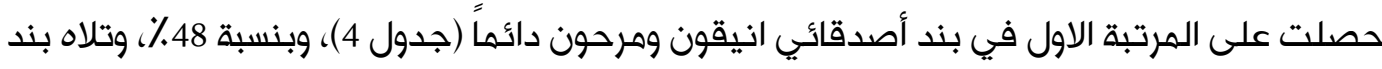
أصدقائي من ذوي الاخلاق الحسنة وبنسبة 32٪ ثم بند أصدقائي أذكياء ومتفوقون دراسياً جاء في المرتبة الاخيرة بنسبة 20٪، في حين جاء بند أصدقائي أذكياء ومتفوقون دراسياً جاء في المرتبة الاولى لنى وهن حيث الاجابة ب(نادراً) جاء بند أصدقائي أذكياء وهتفوقون دراسياً في المرتبة الاولى وبنسبة 46٪، وتلاه بند أصدقائي من ذوي الاخلاق الحسنة 35٪ ثم بند أصدقائي انيقون وهرحون دائماً بنسبة

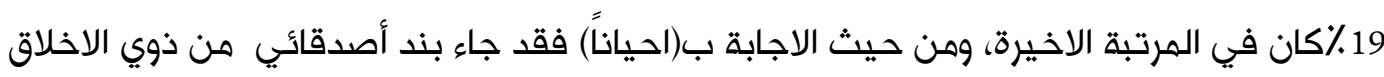

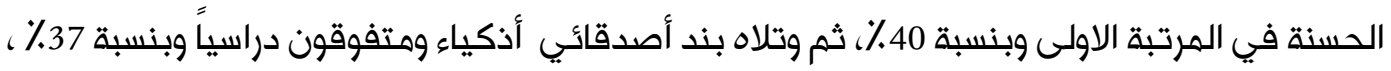
وترجع بند أصدقائي انيقون ومرحون دائماً الى الهرتبة الاخيرة وبنسبة 23٪، وكان مجموع الاجابة بتكرار(دائماً) 174في حين كان مجموع التكرار(نادراً) 62 وتكرار (احياناً) 113

جدول رقم (4) لجابات عينة بثود محور (خصائص الاصدقاء)

\begin{tabular}{|c|c|c|c|c|c|c|}
\hline النسبة\% & ك/ احياناً & النسبة\% & ك/نادرا & النسبة\% & ك/ دائما & البنود البود \\
\hline 40 & 39 & 35 & 25 & 32 & 56 & أصدقائي من ذوي الاخلاق الحسنة \\
\hline 37 & 52 & 46 & 23 & 20 & 34 & أصدقائي أذكياء ومتفوقون دراسياً \\
\hline 23 & 22 & 19 & 14 & 48 & 84 & أصدقائي انيقون ومرحون دائماً \\
\hline- & 113 & - & 62 & - & 174 & المجموع \\
\hline
\end{tabular}

\section{رابعاً: نتأُج استبانة محور دور الاصدقاء}

أظهرت نتائج اجابات الطلبة، على البنود الثلاثة في محور دور الاصدقاء بان الاجابة ب(دائماً) لم تحصل على المرتبة الاولى الا انها حصلت على اعلى نسبة74\% في بند الجأ الى أصدقائي في الظروف الصعبة في (جدول5)، وتلاه بند اطلع أصدقائي على خصوصياتي بنسبة 17\%،اما بند اذا طلب صديقي ان اتغيب عن الدوام اوافق، فقد حصل على نسبة10٪، وجاء هذا الاخير بالمرتبة الاولى لهي من حيث الاجابة ب(نادراً) وبنسبة 44\% وتلاه بند اطلع أصدقائي على خصوصياتي بنسبة 34٪، في حين جاء بند الجأ الى أصدقائي في الظروف الصعبة وبنسبة 23٪، ومن حيث الاجابة ب(احياناً) فقد جاء بند اذا طلب صديقي ان اتغيب عن الدوام اوافق، فقد حصل على نسبة41\% في المرتبة الاولى، ثم وتلاه بند اطلع أصدقائي على خصوصياتي بنسبة39٪، وترجع بند الجأ الى أصدقائي في الظروف

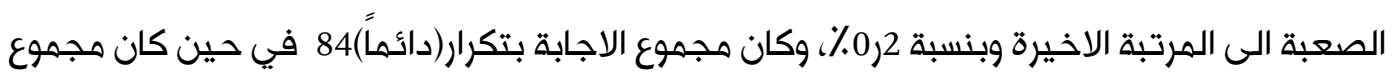

Abdullah, M. (2019). Effect of friendship on adolescence (school Al-Fayhaa Model). Journal Port Science Research, 2(3), 357-374. doi.org/10.36371/port.2018.02.3.2 
التكرار(نادرا) 133 وتكرار (احياناً) 135، وتشير هذه النسبة الى تأثير الصديق على المراهق وان كان هناك تراوح بين( نادراً واحياناً) .

جدول رقم (5) /جابات عيئة في بئود محور (دور الاصدقاء)

\begin{tabular}{|c|c|c|c|c|c|c|}
\hline النسبة\%٪ & ك/احياناً & النسبة\%٪ & ك/ نادرا & النسبة٪\% & ك/ كائما & البنود البود \\
\hline 41 & 55 & 44 & 58 & 10 & 8 & إذا طلب صديقي ان اتغيب عن الدوام اوافق \\
\hline 0.2 & 27 & 23 & 30 & 74 & 62 & الجأ الى أصدقائي في الظروف الصعبة \\
\hline 39 & 53 & 34 & 45 & 17 & 14 & اطلع أصدقائي على خصوصياتي \\
\hline - & 135 & - & 133 & - & 84 & المجموع \\
\hline
\end{tabular}

\section{الخلاصة}

تعد المراهقة من اصعب المراحل التي يمر بها الفرد، ويتم نشأته فيها ليصبح مواطن يتحمل المسؤولية ينفع نفسه وبلده، ويمر التلاميذ بهذه الحالة في مرحلة المتوسطة والاعدادية والتي تكون حرجة ومهمة في نفس الوقت، وتتميز بصعوبات نفسية وحركية، جسمية انفعالية، وعقلية مصطحب بانفعالات وتغيرات بيولوجية فيزيولوجية تستمر الى غاية سن الرشد وتكون وما ينجز عن هذه المشاكل والصعوبات وعقبات تعكر حياة المراهق فمن الضروري عدم تركه وحده ووجب مساعدته على تخطيها، وتحقيقا لمبدأ التكامل وجب التعاون من البيت والمدرسة والهجتمع أعانة الهراهق وتوجيهه حتى تنتهي هذه الفترة بسلام، وعملنا كتربويين يحتم علينا التوجيه والنصح لهذه الشريحة من اولادنا، ومحاولات تنمية التطور النفسي، والانفعالي، والاجتماعي، والجسهي، والحركي، ليكون للتلميذ مكانة ومركز بين اصحابه، وتكيفه مع البرامج التعليمية.

\section{النتائج والتوصيات}

1) ومن أهم التوصيات التي توصلت اليها لتكوين علاقات صداقة حقيقية بين الهراهقين وعبور

$$
\text { هذه المرحلة بسلام هي: }
$$

2) إتاحة الفرصة من الاهل للأبناء منذ الصغر للاختلاط مع اقرانهم وتكوين صدقات معهم وفق

$$
\text { اسس سليمة تقوم على التعاون والاحترام المتبادل. }
$$

3) تشجيع العمل الجماعي والنشاطات الجماعية والحفلات والرحلات في الهدارس بم يتيح للطلبة

$$
\text { تكوين علاقات صداقة سليمة فيما بينهم. }
$$

4) توظيف حفلات التعارف التي تجريها المدارس في بداية العام الدراسي، للحديث عن الحياة

المدرسية، وأهمية التعامل مع الاصدقاء في الجوانب النفسية والاجتماعية والدراسية.

عبدالله، مريه مجيد. (3519)، (2019). تأثير الصداقة على المراهق (مدرسة الفيحاء نموذجاً). Journal Port Science Research، 
5) عقد لقاءت دورية بين طلبة المدارس الاخرى للمسابقات الدورية مما يتيح لهم فرص التعارف

$$
\text { البناء وتوفير الاجواء لتكوين صدقات بين بعضهم. }
$$

6) ادخال مواضيع خاص عن مفهوم الصداقة ومكوناتها، وخصائصها في المقررات الدراسية مها يعلههم معنى الصداقة وكيفية التعامل مع الصديق.

الإهداء أهدي هذا الجهد المتواضع إلى من فارقني في كبري وواراه الثرى والدي العزيز عسى أن أكون بارةً به.

\section{References}

[2] لابي عبد الرحمن الخليل بن احمد الفراهيدي: تحقيق مهدي المخزوهي، ابراهيم السامرائي. (1923). العين. الجمهورية العراقية، وزارة الثقافة والاعلام، دار الرشيد، توزيع الدار الوطنية، 1982.

[3] أبو بكر محمد بن الحسن بن دريد الأزدي(321هـ)،حقيق: (مزي منير بعلبكي. جمهرة اللغة. دار العلم للملايين، الطبعة الاولى، بيروت.(1987). [4] محمد بن القاسم بن محمد بن بشار، أبو بكر الأنباري، المحقق: د. حاتم صالح الضامن (1922). الزاهر في معاني كلمات الناس. الطبعة الأولى مؤسسة الرسالة - بيروت. [5] عياض بن موسى بن عياض بن عمرون اليحصبي السبتي، أبو الفضل. (د.ت). مشارق الأنوار على صحاح الآثار. المكتبة العتيقة ودار التراث.

[6] علي بن محمد السيد الشريف الجرجاني (816هـ)، تحقيق: محمد صديق الهنشاوي. معجم التعريفات. دار الفضيلة، د. ط، مصر- القاهرة. (2004).

[7] محمد بن أحمد بن الأزهري الهروي، أبو منصور(770هـ)، تحقيق: محمد عوض مرعب. تهذيب اللغة. دار إحياء التراث العربي،الطبعة الاولى، بيروت. (2001.

[8] أحمد بن محمد بن علي الفيومي ثم الحموي، أبو العباس(370هـ). الهصباح الهنير في غريب الشرح الكبير.

$$
\text { المكتبة العلمية، د. ط، بيروت. (د.ت). }
$$

Abdullah, M. (2019). Effect of friendship on adolescence (school Al-Fayhaa Model). Journal Port Science Research, 2(3), 357-374. doi.org/10.36371/port.2018.02.3.2 
j. port. sci. res.
ISSN: $2616-7441$

[9] محمد بن مكرم بن على، أبو الفضل، جمال الدين ابن منظور الأنصاري الرويفعى الإفريقى، (711هـ). لسان العرب. دار صادر، الطبعة الثالثة، بيروت .1993)).

[10] أحمد مختار عبد الحميد عمر. (2003) .معجم اللغة العربية المعاصرة. عالم الكتب، الطبعة الاولى. (2008.) [11 [أحمد رضا. (1959). معجم متن اللغة. دار مكتبة الحياة، د. ط، بيروت.

[12] خليل ميخائيل معوض. (1971). مشكلات المراهقين في المدن والريف. دار المعارف بمصر، الطبعة الاولى، مصر- القاهرة.

[13] نوري الحافظ. المراهق. (1990). المؤسسة العربية للدراسات والنشر، الطبعة الثانية، لبنان- بيروت. [14] أحمد أوزي. المراهق والعلاقات المدرسية. (2000). دار النجاح الجديدة، الطبعة الاولى، الدار البيضاء؛ المغرب.

[15] عبد العزيز القوصي. (1987). علم النفس أسسه وتطبيقاته التربوية. النهضة العربية، الطبعة الاولى، مصربيروت.

[16] عبد القادر طه فرج. (د.ت). معجم علم التحليلي والنفسي. دار النهضة للطباعة، الطبعة الاولى، بيروت. [17] أبو عبد الله محمد بن أحمد بن أبي بكر بن فرح الأنصاري الخررجي شمس الدين القرطبي (671هـ)، تحقيق: أحمد البردوني وإبراهيم أطفيش. (1964). .الجامع لأحكام القرآن تفسير القرطبي. دار الكتب المصرية، الطبعة

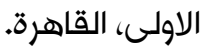

[18] محمد بن إسماعيل أبو عبدالله البخاري الجعفي، تحقيق: محمد زهير بن ناصر الناصر. (2001). الجامع المسند الصحيح الهختصر من أمور رسول الله صلى الله عليه وسلم وسننه وأيامه صحيح البخاري. دار طوق النجاة،

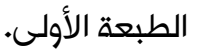

[19] محمد بن جرير بن يزيد بن كثير بن غالب الآهلي، أبو جعفر الطبري (310هـ) ، تحقيق: د.عبد الله بن عبد المحسن التركي. (2001). جامع البيان عن تأويل آي القرآن. دار هجر للطباعة والنشر، الطبعة الأولى. بن. [17] الزحيلي، وهبة بن مصطفى. (2001). التفسير الوسيط. دار الفكر الطبعة الاولى، دمشق. [18] الجعفي، محمد بن إسماعيل أبو عبدالله البخاري، تحقيق: محمد زهير بن ناصر الناصر. (2001). الجامع

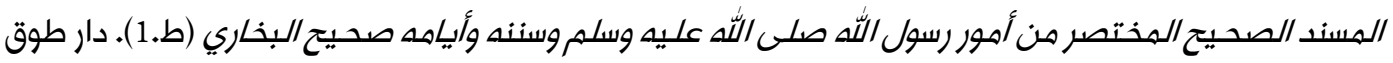


[19] الطبري، محمد بن جرير بن يزيد بن كثير بن غالب الآملي، أبو جعفر، تحقيق: عبد الله بن عبد المحسن

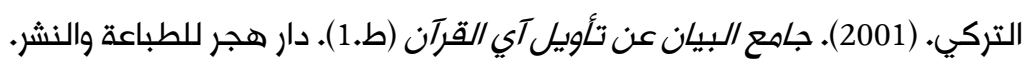
[20] الزحيلي، وهبة بن مصطف. (2001).التفسير الوسيط. (ط.1). دمشق: دار الفكر.

[21] البيضاوي، الناصر الدين أبو سعيد عبد الله بن عمر بن محمد الشيرازي، تحقيق: محمد عبد الرحمن المرعشلي. (1997).أنوار التنزيل ؤسرار التأويل (ط.1). بيروت: دار إحياء التراث العربي.

[22] الخوارزمي، أبو القاسم محمود بن عمر الزمخشري، تحقيق: عبد الرزاق المهدي. (د. ت).الكشاف عن حقائق التنزيل وعيون الأقاويل في وجوه التأويل (د. ط). بيروت: دار إحياء التراث العربي.

[23] جلال الدين محمد بن أحمد المحلي، وجلال الدين عبد الرحمن بن أبي بكر السيوطي. (د.ت). تفسير الجلالين (ط.1). القاهرة: دار الحديث.

[24] مسلم بن الحجاج أبو الحسن القشيري النيسابوري، تحقيق: محمد فؤاد عبد الباقي. (د.ت). المسند الصحيح المختصر بنقل العدل عن العدل إلى رسول اللهّ ئك (دمط). بيروت: دار إحياء التراث العربي.

[25] النووي، أبو زكريا محيي الدين يحيى بن شرف. (1972). المنهاج شرح صحيح مسلم بن الحجاج (ط.2).

$$
\text { بيروت: دار إحياء التراث العربي. }
$$

[26] العيني، أبو محمد محمود بن أحمد بن موسى بن أحمد بن حسين الغيتابي الحنفي بدر الدين. (د.ت).عمدة

$$
\text { القاري شرح صحيح البخاري (د. ط). بيروت: دار إحياء التراث العربي. }
$$

[27] الترمذي، محمد بن عيسى بن سورة بن موسى بن الضحاك، أبو عيسى، تحقيق: أحمد محمد شاكر وآخرون.

$$
\text { (1975). سنن الترمذي (ط.2). مصر شركة مكتبة ومطبعة مصطفى البابي الحلبي. }
$$

[28] الشافعي، محمد علي بن محمد بن علان بن إبراهيم البكري الصديقي، تحقيق: خليل مأمون شيحا. (2004).

دليل الفالحين لطرق رياض الصالحين (ط.1). لبنان- بيروت: دار المعرفة للطباعة والنشر والتوزيع.

[29] الألباني، أبو عبد الرحمن محمد ناصر الدين، بن الحاج نوح بن نجاتي بن آدم الأشقودري. (د. ت). صحيح

$$
\text { الجامع الصغير وزياداته (د.ط). المكتب الإسلامي. }
$$

[30] القاهري، زين الدين محمد المدعو بعبد الرؤوف بن تاج العارفين بن علي بن زين العابدين الحدادي ثم

$$
\text { المناوي. (1937). فيض القدير شرح الجامع الصغير (ط.1). مصر: المكتبة التجارية الكبرى. }
$$

[31] الغزالي، ابي حامد محمد بن محمد بن محمد. (2005). أحياء علوم الدين. (ط.1)، لبنان- بيروت: دار ابن 
j. port. sci. res.
ISSN: $2616-7441$

[32] القزويني، ابن ماجة أبو عبد الله محمد بن يزيد، تحقيق: محمد فؤاد عبد الباقي (د.ت).سنن/بن ماجه (د.ط).

$$
\text { دار إحياء الكتب العربية- فيصل عيسى البابي الحلبي. }
$$

[33] البيهقي، أحمد بن الحسين بن علي بن موسى الخسروجردي الخراساني، أبوبكر، تحقيق: عبد العلي عبد الحميد حامد، واخرون. (2002). شعب الإيمان. (ط.1.)، الهند- ببوهباي: مكتبة الرشد.

[34] الصنعاني، محمد بن إسهاعيل بن صلاح بن محمد الحسني الكحلاني، تحقيق: محمَّدَ إسحاق محمَّد إبراهيم.

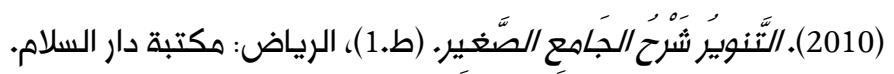

[35] الاشول، عادل عز الدين. (2008). علم نفس النمو. مصر: مكتبة أنجلو الهصرية، (د.ط). [36] بكار،عبد الكريم. (2010). المراهق كيف نفهمه وكيف نوجهـ(ط.1.). مصر- القاهرة: دار السلام. [37] بيكور، سالرز ، ترجمة: حسن كمال.(1964) ـأسس التربية البدنية (د.ط). (د.ن). [38] الباهي، فؤاد السيد. (1975). الاسس النفسية للنمو (ط.4). القاهرة: دار الفكر العربي. [39] صالح ،عبد العزيز. (1976). التربية وطرق التدريس(د.ط). دار المعارف. [40] عقل، فاخر. (1978). علم النفس التربوي. (د.ط)، دار الملايين. [41] علوي، محمد حسن. (1992). علمم النفس الرياضي. (د.ط). القاهرة: دار المعارف. [42] فهمي، مصطفى. (1954). سيكولوجية الطفل والمراهقة. (د.ط)، مصر: مكتبة مصر. [43] محمد، سعد. (د.ت). سيكولوجية المراهق. (د.ط). القاهرة: دار المعارف. [44] زهران، حامد عبد السلام. (1977). علمرالنفس النمو الطفولة والمر/هقة. (ط.4)، مصر- القاهرة: دار المعارف. [45] عوض، عباس محمود. (1999). علم نفس النمو. (د. ط)، مصر: دار المعرفة الجامعة. [46] الجسماني، عبد العلي. (1994). سيكولوجية الطفولة والمراهقة وحقائقها الأساسية. (ط.2)، الدار العربية للعلوم. [47] الشماس، د. عيسى الشماس. (2012-28). الصداقة عند الشباب الجامعي. مجلة جامعة دمشق، (العدد الثاني). 